\title{
Costs of visiting babies in special care baby units*
}

\author{
M A SMITH AND J D BAUM \\ University Department of Paediatrics, John Radcliffe Hospital, Oxford
}

SUMMARY Parents of babies who spend long periods in special care baby units are faced with the problem of developing a caring relationship with their baby. The journeys to and from the hospital pose additional financial and social stress on parents who are already under considerable emotional strain. A survey into the financial costs incurred by parents visiting their babies in six hospitals during a period of 2 months was conducted using questionnaires. Complete data were available for analysis from four hospitals on 126 babies (98 inborn and 28 outborn). For babies inborn in a maternity hospital, the mean cost of visting for parents with a car was £4l (range 1-336) and for those who travelled by public transport the mean cost was $£ 30$ (range 2-151). For babies born outside the hospital and transferred to a special care baby unit, the mean cost of visiting for parents with a car was $£ 123$ (range 11-518), and for those who travelled by public transport the mean cost was $£ 46$ (range 16-80). There was almost no financial assistance available to help these families, one-third of whom had at least one serious social problem.

It is generally considered important for parents to maintain close links with their newborn babies. This is to ensure that the parents have the best possible chance of developing the appropriate caring relationship with their baby, a relationship popularly known as 'bonding'. This is particularly important for babies who begin life with the disadvantages of low birthweight and sickness (resulting in prolonged stay in the maternity hospital) since among this group of families social and domestic problems are over-represented. ${ }^{1}$

In order to obtain some indication of the problems which parents face while visiting their babies in special care baby units a questionnaire was devised to measure the travelling costs.

\section{Method}

Eleven special care baby units were invited to participate in a 2-month prospective survey of parent visiting. Returns relating to the months of October and November 1980 were received from six units, but two sets of data were incomplete. The results set out below relate to the forms received from the remaining four hospitals.

Since the purpose of the questionnaire was to consider the problems that parents have in visiting

* Report prepared for the Standing Joint Committee of the British Paediatric Association and Royal College of Obstetrics and Gynaecology babies who remain for prolonged periods in a special care baby unit, it was decided to exclude any baby who died within one week of birth, or any baby whose stay in hospital was less than 7 days after his mother was discharged. Furthermore, since it seemed likely that the problems for the parents of babies inborn in a maternity unit would be different from those of babies transferred to another maternity unit for neonatal intensive care, separate analysis of these two categories was carried out.

\section{Results}

A total of 186 forms was received from four maternity hospitals (Table 1). Eight babies were excluded because they died within one week of birth; 52 babies were excluded because their stay in hospital was less than 7 days after their mothers' discharge. The analysis was therefore based on a total of 126 babies. Three of these babies died but each had spent more than one week in the baby unit after his mother was discharged. There were 98 inborn babies and 28 outborn (including one baby who was admitted because of maternal complications).

Some mothers from district general hospitals may have been transferred to the regional maternity hospital with a fetus in utero. Since we had no accurate information on the number of referrals, the babies will have been included in the analysis as 'inborn patients' in the maternity unit. 
Table 1 Number of babies studied and the maternity unit

\begin{tabular}{|c|c|c|c|c|c|}
\hline & Manchester & Oxford & Belfast & Liverpool & Totals \\
\hline \multicolumn{6}{|l|}{ Admissions } \\
\hline Inborn & 28 & 30 & 31 & 55 & 144 \\
\hline Outborn & 6 & 7 & 12 & 17 & 42 \\
\hline Total & 34 & 37 & 43 & 72 & 186 \\
\hline Deaths & $3 *$ & 0 & 0 & $8+$ & 11 \\
\hline $\begin{array}{l}\text { Discharged }<1 \text { week after the } \\
\text { mother discharged }\end{array}$ & 0 & 2 & 9 & 41 & 52 \\
\hline Analysis & 34 & 35 & 34 & 23 & 126 \\
\hline Based on inborn & 28 & 28 & 27 & 15 & 98 \\
\hline Based on outborn & 6 & 7 & 7 & 8 & 28 \\
\hline
\end{tabular}

*Included in analysis (babies survived $>1$ week and therefore needed visiting), texcluded from analysis (died within 1 week of birth).

Table 2 Gestational age, birthweight, and time spent in a special care baby unit for all babies included in the analysis

\begin{tabular}{lcc}
\hline Variable & Mean & Range \\
\hline Gestational age (weeks) & 32 & $24-41$ \\
Birthweight (g) & 1755 & $650-4955$ \\
Time spent in special care baby unit (weeks) & $3 \cdot 7$ & $1 \cdot 0-16 \cdot 0$ \\
Inborn & $6 \cdot 0$ & $1 \cdot 6-16 \cdot 0$ \\
Outborn & \\
\hline
\end{tabular}

The gestational age, birthweight, and time spent in the baby unit for all babies included in the analysis are shown in Table 2. Forty-two per cent of all the babies admitted weighed less than $1500 \mathrm{~g}$. Twenty-seven $(22 \%)$ of the 126 families were in social classes I and II; 45 (35\%) were in social class III; $25(20 \%)$ were in social classes VI and V; $9(7 \%)$ were unemployed and $20(16 \%)$ could not be classified (for example members of the armed forces and students). ${ }^{2}$

Social problems. Forty-one ( $33 \%$ ) of the 126 families had at least one serious social problem. Thirteen fathers were unemployed, 14 mothers were unmarried, 10 families were on social security, and 21 families had other social problems. Their babies were smaller than those of families without any social problems (1590 compared with $1830 \mathrm{~g}$ ) and therefore spent longer in hospital (5 compared with 4 weeks).

Financial difficulties. Financial difficulties were recognised in $30(24 \%)$ families. These families were found to differ from the remaining 96 families (who expressed no financial difficulties) in the gestational age of their babies. This was 30 weeks compared with 33 weeks for the remaining 96 babies $(P<0.01$, Student's $t$ test).

Fifteen of these 30 families had received financial assistance: the mean sum of money received was $£ 22$ (range 3-63).

Visiting. The majority of parents, 90 (71\%) of 126 , travelled to the hospital by car, $30(24 \%)$ travelled by bus or train, and 4 lived close enough to the hospital to walk. One father did not visit his baby at all because his wife had died; and there are no data about travelling for one other family.

A breakdown of the distance from home to hospital (one way) is shown in Table 3. One-third of the parents lived further than 20 miles from the hospital. The average distance travelled by all families from home to hospital was 19 (range 0-83) miles. This gave an average 'round trip' or total distance of 38 miles. The mean total distance travelled by parents of inborn babies was 26 (range 2-166) miles, and for those of outborn babies was 82 (range 0-160) miles. The average time for all families for a round trip was $1 \frac{1}{2}$ hours (range 10 minutes to 6 hours).

Of the total of 126 families, $66(52 \%)$ visited their baby at least once a day, $22(17 \%)$ parents visited between 4 and 6 times a week, the remaining 36 $(29 \%)$ parents visited $1-3$ times a week. One set of parents visited their baby only 2 or 3 times in a 9-week period. They were unmarried, and the mother had one child in care as a result of child abuse.

Factors influencing visiting. In order to obtain some idea of the factors which might influence visiting frequency, the parents (inborn and outborn considered together) were divided into two groups: the 49 who visited 1-4 times a week (group A, mean number of visits a week $=2 \cdot 7$ ), and the 71 who

Table 3 Distances travelled between home and hospital for parents of inborn compared with outborn babies

\begin{tabular}{lllll}
\hline $\begin{array}{l}\text { Distance from home } \\
\text { to hospital (miles) }\end{array}$ & $\begin{array}{l}\text { Inborn } \\
(n=98)\end{array}$ & $\begin{array}{l}\text { Outborn } \\
(n=28)\end{array}$ & \multicolumn{2}{l}{ Totals } \\
\cline { 4 - 5 } & & No & $(\%)$ \\
\hline $0-5$ & 38 & 2 & 40 & $(32)$ \\
$6-10$ & 22 & 0 & 22 & $(17)$ \\
$11-20$ & 18 & 4 & 22 & $(17)$ \\
$>20$ & 20 & 22 & 42 & $(33)$ \\
\hline
\end{tabular}


Table 4 Mean costs for parents of inborn babies who travel by car or public transport

\begin{tabular}{|c|c|c|c|c|}
\hline & \multicolumn{2}{|c|}{$\begin{array}{l}\text { Car users } \\
(n=67)\end{array}$} & \multicolumn{2}{|c|}{$\begin{array}{l}\text { Public transport } \\
(n=26)\end{array}$} \\
\hline & Mean & Range & Mean & Range \\
\hline $\begin{array}{l}\text { Distance of complete } \\
\text { journey (miles) }\end{array}$ & 30 & $2-166$ & 15 & $2-72$ \\
\hline $\begin{array}{l}\text { No of journeys } \\
\text { per week }\end{array}$ & $7 \cdot 1$ & $1-20$ & $5 \cdot 4$ & $1-14$ \\
\hline $\begin{array}{l}\text { Length of stay in } \\
\text { baby unit after } \\
\text { mother's discharge } \\
\text { (weeks) }\end{array}$ & $3 \cdot 5$ & $1-16$ & $4 \cdot 4$ & $1-11$ \\
\hline Cost per journey *(f) & $2 \cdot 0$ & $0 \cdot 2-12 \cdot 0$ & $1 \cdot 6$ & $0 \cdot 4-7 \cdot 2$ \\
\hline $\begin{array}{l}\text { Total cost of } \\
\text { visiting* }(£)\end{array}$ & 41 & $0 \cdot 4-336 \cdot 0$ & 30 & $1 \cdot 6-151 \cdot 2$ \\
\hline $\begin{array}{l}\text { Cost of visiting at } \\
9.2 \mathrm{p} / \mathrm{mile}+(f)\end{array}$ & 55 & $1-333$ & - & - \\
\hline
\end{tabular}

*Parents' stated costs, †calculated running costs.

Table 5 Mean costs for parents of outborn babies who travel by car or public transport

\begin{tabular}{|c|c|c|c|c|}
\hline & \multicolumn{2}{|c|}{$\begin{array}{l}\text { Car users } \\
(n=23)\end{array}$} & \multicolumn{2}{|c|}{$\begin{array}{l}\text { Public transport } \\
(n=4)\end{array}$} \\
\hline & Mean & Range & Mean & Range \\
\hline $\begin{array}{l}\text { Distance of complete } \\
\text { journey (miles) }\end{array}$ & 90 & $32-160$ & 42 & $10-72$ \\
\hline No of journeys/week & $4 \cdot 2$ & $1-10$ & $3 \cdot 8$ & $2-7$ \\
\hline $\begin{array}{l}\text { Length of stay in } \\
\text { baby unit (weeks) }\end{array}$ & $5 \cdot 8$ & $2-16$ & $7 \cdot 3$ & $3-10$ \\
\hline Cost per journey* $(f)$ & $2 \cdot 5$ & $0 \cdot 8-12 \cdot 0$ & $2 \cdot 1$ & $0 \cdot 8-3 \cdot 8$ \\
\hline $\begin{array}{l}\text { Total cost of } \\
\text { visiting* }(£)\end{array}$ & 123 & $11-518$ & 46 & $16-80$ \\
\hline $\begin{array}{l}\text { Cost of visiting at } \\
9.2 \mathrm{p} / \mathrm{mile}+(\mathrm{f})\end{array}$ & 200 & $26-799$ & 一 & 一 \\
\hline
\end{tabular}

*Parents' stated costs, †calculated running costs.

visited at least 5 times a week (group B, mean number of visits $=8 \cdot 4$ ).

The most important factor influencing the visiting patterns of the parents appeared to be the distance between home and hospital, and also the cost. Group A parents had a mean distance of 28 miles to travel compared with a mean of 13 miles for group $\mathrm{B}(\mathrm{P}<0 \cdot 001$, Student's $t$ test $)$.

The statistically significant factors (using the $\chi^{2}$ test) which may have been associated with a reduced visiting rate were the birth of the baby outside the hospital $(P<0 \cdot 05)$, the baby having an unmarried mother $(P<0.05)$, the presence of any social problem within the family $(P<0.05)$, and transport difficulties $(P<0 \cdot 05)$.

Costs for an average family visiting a baby in the special care baby unit. The distance from the hospital is affected by whether the baby was inborn or outborn; the cost of the journey is influenced by whether this is arrived at from public transport figures or the calculated cost of travel by private car.
In order to arrive at a cost for visiting, questions were asked relating to the distance and cost of the journey. For those travelling by car (90 parents), the costs were calculated using the AA running cost of 9.2 pence per mile. This figure includes petrol, oil, tyres, servicing, and repairs and replacements for cars of 1001-1500 cc engine capacity. ${ }^{3}$ Standing charges of $15.0 \mathrm{p} / \mathrm{mile}$ (which include licence, insurance, depreciation etc) have not been included, which means that the actual costs for car drivers is somewhat higher than the results quoted here. The detailed analysis of these costs, separating inborn from outborn babies, and car users from those travelling by public transport are shown in Tables 4 and 5 .

The average cost for 'an average family' with the baby inborn in a maternity hospital was as follows:

Public transport

$£ 30$

Petrol

$£ 41$

Calculated cost of visiting by car $\quad £ 55$ (at $9 \cdot 2 \mathrm{p} / \mathrm{mile}$ )

(These costs may be slightly too high, because of the inclusion of some babies born in a maternity hospital after their mothers had been transferred with a fetus in utero from a district general hospital).

For the baby born outside the hospital and transferred to a baby unit the average cost was:

Public transport

$£ 46$

Petrol

$£ 123$

Calculated cost of visiting by car (at $9 \cdot 2 \mathrm{p} / \mathrm{mile}$ )

$£ 200$

\section{Discussion}

The purpose of this questionnaire was to measure the cost for families visiting their babies in special care baby units, using this as some indicator of the overall stress associated with the special care of a low birthweight sick newborn infant. The distance from the hospital will vary, being influenced particularly by the state of development of regional services for intensive care of the newborn infant.

The number of families who received any financial aid and the level of the support is surprisingly low. Of the four hospitals included in this study, three had a half-time social worker and one hospital had no social work time specifically allocated for the special care baby unit. One hospital spent $£ 2000$ a year on travelling expenses (which only partly met the needs of the poorest families), one hospital spent $£ 200$, one hospital did not have accurate figures, and one hospital had no money for visiting expenses.

Many other factors were considered in the survey, but have not been analysed in detail in this report. It is, for instance, noteworthy that of the 61 mothers who had planned to breast feed their babies only 29 
were successful in sustaining lactation. These were the mothers with bigger babies of greater gestational ages, who lived nearer the hospital, and thus had shorter and cheaper journeys in comparison with the mothers who were unsuccessful in sustaining lactation.

It is important for the mothers of low birthweight and sick babies to spend as much time with them as possible in order to develop and maintain the caring relationship necessary to cope with them after discharge from hospital. The purpose of this survey was to draw attention to the very considerable costs of 'satisfactory visiting' and the meagre financial support for parents who have difficulty in visiting their babies. It should be recognised that visiting babies in hospital presents additional serious social and financial stress for parents, at a time when the whole family is perhaps at its most vulnerable.

We thank Miss P Townshend and Mrs C Emery,
John Radcliffe Hospital, Oxford; Dr N Coad, Liverpool Maternity Hospital; Ms M Wilson, St Mary's Hospital, Manchester; the staff of the Royal Maternity Hospital, Belfast, for assistance; Miss M Cushion who helped with the analysis.

\section{References}

1 Chamberlain R. The week. In: Chamberlain R, Chamberlain G, Howlett B, Claircaux A. British births 1970. Vol. I. London: Heinemann, 1975: 16-7.

2 Office of Population Censuses and Surveys. Classification of occupations and coding index. London: HMSO, 1980.

3 Automobile Association. Form Tech 9. Twickenham: AA Technical Services Department, 1982.

Correspondence to Dr J D Baum, Department of Paediatrics, John Radcliffe Hospital, Headington, Oxford OX3 9DU.

Received 5 October 1982

\section{International meetings}

\section{1-13 May 1983, Graz}

European Society for Paediatric Gastroenterology and Nutrition

Further details: Professor B Hadorn, University of Graz, Auenbruggerplatz, A-8036, Graz, Austria

\section{August-2 September 1983, Hanover}

Sixth International Symposium of Paediatric Nephrology

Further details: Congress Project Management, Gunther Sachs, Letzter Hasenpfad 61, D-6000 Frankfurt 70, Federal Republic of Germany

\section{August-1 September 1983, Budapest}

European Society for Paediatric Endocrinology

Further details: Dr F Peter, Buda Children's Hospital, 1277 Budapest 23, POB 14

\section{4-8 September 1983, France}

European Society for Paediatric Research

Further details: Professor Roger Jean, 8 Rue Guillaume De Nogaret-F-34000 Montpellier, France

\section{2-25 September 1983, Poland}

European Paediatric Respiratory Society

Further details: Professor Jan Rudnik MD, L'Institut National de la Mere et de l'Enfant, Rabka Section, 34-410 Rabka, ul. Parkowa 2

\section{7-12 November 1983, Manila}

XVII International Congress of Paediatrics

Further details: Professor Perla D Santos Ocampo, President, XVII International Congress of Paediatrics, P O Box EA 100, Ermita, Manila, Philippines 